\title{
Multidepot Two-Echelon Vehicle Routing Problem for Earthwork Allocation Optimization
}

\author{
Qinglong Zhang $\mathbb{D}^{D}$, Naifu Deng ${ }^{\mathbb{D}}$, Yanwen Zhu, and Zhenping Huang \\ Department of Civil Engineering, School of Civil and Resource Engineering, University of Science and Technology Beijing, \\ Beijing 100083, China \\ Correspondence should be addressed to Naifu Deng; nden8417@163.com
}

Received 9 December 2021; Accepted 6 January 2022; Published 29 January 2022

Academic Editor: Xiangtao Li

Copyright ( $) 2022$ Qinglong Zhang et al. This is an open access article distributed under the Creative Commons Attribution License, which permits unrestricted use, distribution, and reproduction in any medium, provided the original work is properly cited.

\begin{abstract}
Prior to the construction of most engineering projects, earthwork is a complex and time-consuming task, requiring iterative operations in civil engineering. The effectiveness of earthworks determines the cost of many AEC (architecture, engineering, and construction) projects (e.g., road, embankment, railway, and slope engineering). As a result, creating effective earthwork planning is critical. The earthwork allocation problem is simplified in this study to the vehicle route problem (VRP), which is often studied in the field of transportation and logistics. An optimization model for the earthwork allocation path based on the modified genetic algorithm with a self-adaptive mechanism is developed to work out the global optimal hauling path for earthwork. The findings of the study are also used to shape the basic topographic shape of the Winter Olympic Skiing Course Project. Furthermore, a comparative study with the former methods is conducted to validate the performance of our proposed method on tackling such a multidepot two-echelon vehicle routing problem. Because of its flexibility, this optimization model is extremely compatible with various evolutionary methods in many fields, making future development viable and practicable.
\end{abstract}

\section{Introduction}

Earthwork allocation is a substantial and repetitive task required for the majority of AEC (architecture, engineering, and construction) projects $[1,2]$. Earthwork is the process of leveling or shaping the ground in a target area by moving or handling the geological materials that make up the target area. This geological material allocation usually includes excavation, loading, handling, unloading, and compaction operations in different areas. Sometimes it may also include some intermediate steps, such as material mixing or processing $[3,4]$. Because of the complexity of earthwork activities, the volume of work is large and often accounts for more than $50 \%$ of the total project cost [5]. In particular, among the above steps, transporting geotechnical materials from one location to another is in most cases the most expensive $[6,7]$. Since earth distribution is usually a continuous and repeatable iterative process, finding an effective technical approach to rationalize the earth deployment path can yield significant economic benefits, such as reduced fuel consumption or carbon emissions $[1,8]$.

Earthwork allocation is essentially an extended application of the vehicle path problem (VRP). VRP is a combinatorial dynamic planning problem that seeks to utilize a fleet of vehicles, such as trucks, to serve a certain number of customers with different cargo requirements under certain constraints, such as the delivery time or load capacity of nominated vehicles $[9,10]$. It primarily refers to a set of issues in which an ideal route for a fleet of vehicles based on one or more depots may be identified for a number of geographically separated consumers $[11,12]$. Figure 1 represents the schematic diagram of a single-depot VRP. The vehicle route problem, first proposed by Dantzig and Ramser in 1959 [11], is a critical problem in transportation and logistics. Since its inception, the problem has piqued the interest of experts and researchers, and it has aided the development of transportation, aviation, navigation, communications, electric power, computer science, and other 

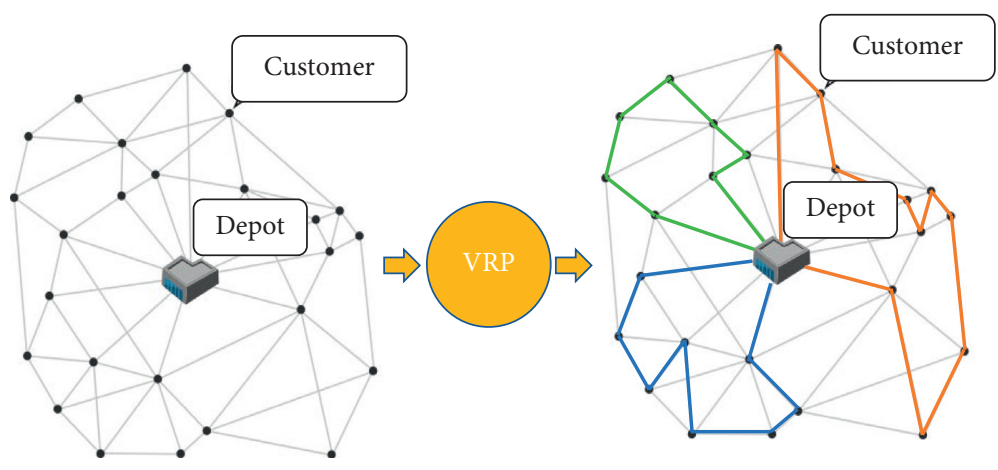

FIGURE 1: Schematic diagram of a single-depot VRP (also see in [6]).

fields in some ways. The VRP, on the other hand, is a nondeterministic polynomial hard (NP-hard) problem that cannot be solved in polynomial time. In other words, given the existing knowledge, it is impossible to find the exact answer to the problem, or it will take ages to find the exact solution. It is especially true when the task is large-scale. As a result, the current research has changed from finding the perfect answer using an exact algorithm to finding a better solution using a heuristic approach.

The frequently used heuristic algorithms are the genetic algorithm (GA) [13-16], ant colony algorithm (ACA) [17-19], particle swarm optimization algorithm (PSOA) [20-23], simulated annealing algorithm (SAA) [24-26], tabu search algorithm (TSA) [27-29], differential evolution algorithm (DEA) [30], and so on. ACA is adept at path planning problems, in particular, ACA shows great robustness in solving the traveling salesman problem [31]. However, ACA requires a large amount of computation because it usually requires all ants to choose the same route, which is the optimal line. In practical calculation, it is difficult to achieve this situation under a given number of cycles [32]. SAA is universal and robust, which is suitable for parallel processing and complex nonlinear optimization problem, nevertheless, it also relies on higher computation resources and longer computing time [33]. PSOA and TSA are the opposite, it has fast convergence speed, however, it is easy to produce premature convergence problem, especially in dealing with complex multipeak search problems $[33,34]$. DEA and GA are evolutionary algorithms. DEA is modified from GA by improving the mutation operation to accelerate its convergence speed [35], however, fast convergence speed may lead to a premature problem when the initial population is small [36].

In this paper, GA is adopted to study the earthwork allocation path problem as it is one of the earliest algorithms to be applied to the field of transportation [37]. Furthermore, research demonstrates that GA is well-suited to handling NP-hard issues, including various variables, parameters, objectives, and weak connectivity across different areas $[38,39]$. GA can also record numerous solutions at once, and the simultaneous optimization process for multiple solutions can be used to solve multiobjective optimization problems [39]. Furthermore, GA has a better universality and compatibility, which allows for further improvement when combined with other heuristic algorithms [40].
Therefore, this paper focuses on the vehicle route problem to refine the earth allocation problem based on the genetic algorithm. In reality, earth allocation may include multiple vehicle replenishment centers (depots), multiple cutting fields (distribution centers), and multiple filling fields (customers) distributed geographically in a certain range of areas. Before reaching its mileage restriction, each vehicle must return to any replenishment site to refuel. Furthermore, fuel usage varies depending on whether the truck is empty or loaded. Furthermore, each excavation area has a maximum amount of earthwork it can generate. Hence, an excavation area cannot contribute a limitless amount of earthwork to its neighboring filling regions. When the earthwork from their nearest excavation location is depleted, those filling regions must choose another suitable excavation place to furnish the earthwork. In light of the aforementioned restrictions, the goal of this work is to maximize the number of sent trucks and the overall fuel usage throughout the shipping distance. Accordingly, this paper made the following contributions:

(1) This paper constructs a complicated multidepot twoechelon vehicle routing problem (MD-TEVRP) and provides a many-to-many recursive pairing solution based on the genetic algorithm.

(2) A self-adaptive mechanism is designed to control the crossover and mutation rate to manipulate and maintain the diversity of the generated population, which can prevent the local convergence problem and provide robust performance.

(3) The proposed method demonstrates great performance in the case study and comparative study, which provided guidance for the construction of the skiing courses of the Beijing Winter Olympic Games Skiing Center in Yanqing, Beijing.

\section{Model Formation}

2.1. Problem Description. This paper assumes that the earthwork working sites are divided into 4 parts, i.e., the replenishment centers, the cutting fields, the filling fields, and the paths. The replenishment centers, denoted as $j \in J$, are defined as the depots where engineering vehicles (in this paper, dump trucks are mainly considered) can get refueled 
or repaired. Each replenishment center is able to accommodate $I_{j}$ dump trucks that can provide stable and nonstop hauling services at each dispatch, which means these dump trucks will not stop transporting earthworks from the cutting fields to the filling fields until they exhaust all fuel capacity. To this point, earthwork allocation can be regarded as an extension of the vehicle route problem (VRP) with the purpose of transporting the earthwork from several specific places to other different appointed locations. The planning key of earthwork allocation is to transport the required amount of earth volume from the cutting field $k \in K$ and distribute them according to the different earthwork needs of the filling fields $g \in G$. To simplify this problem, this paper defines the volume of earthwork to be excavated in the $k^{\text {th }}$ cutting field as the number of fully loaded dump trucks $b_{k}$ needed to transport away all the dredged earth. Similarly, the volume of earthwork needed in the $g^{\text {th }}$ filling fields demands $c_{g}$ fully loaded dump trucks to unload the earth. It is notable that the earthwork from all cutting fields should be not less than the earthwork needed in all filling fields, namely,

$$
\sum_{k \in K} b_{k} \geq \sum_{g \in G} c_{g}, \quad \forall k \in K, \forall g \in G,
$$

where $b_{k}$ is the total number of fully loaded dump trucks needed to haul all earthwork in $k^{\text {th }}$ cutting field, and $c_{g}$ is the total number of fully loaded dump trucks needed to fill the $g^{\text {th }}$ filling field.

As illustrated in Figure 2, an empty-laden truck is dispatched from the $j^{\text {th }}$ replenishment centers to the $k^{\text {th }}$ cutting field after fully loading with earth and rocks. This truck will move to the $g^{\text {th }}$ filling field and unload the earth and rocks. Depending on its fuel capacity, this truck can either return to one of the replenishment centers to get refueled (in this case, this path for this truck is called one-way path) or head to one of the cutting fields to get loaded again and repeat the earthwork hauling work between the cutting fields and the filling fields (in this case, the path for this truck is called multiway path). In this paper, the maximum mileage of a truck is dynamic based on how often it is fully loaded during each dispatch, i.e., each truck has its own maximum fuel capacity $l_{i j}$, and thus, a fully loaded truck will consume more fuel at each unit hauling distance, and the more frequent it is fully loaded, the less mileage it can guarantee. Practically, earthwork allocation is repetitive, and thus, a multiway transportation path planning for each dump truck is indispensable. On the basis of not exceeding the mileage limit, it is required that a minimum number of dispatched trucks and a global minimum hauling distance are derived accordingly to achieve a minimum fuel consumption for the least carbon emission.

2.2. Objective Model and Constraints. According to the problem illustrated above and the schematic diagram shown in Figure 2, our objective is to find the shortest overall hauling distance and achieve the lowest fuel consumption. Therefore, the objective model can be formulated as follows:

$$
\begin{aligned}
\min Z= & \sum_{j \in J} \sum_{i \in I_{j}} \sum_{k \in K} \sum_{g \in G} \\
& {\left[\alpha\left(d_{i j k} X_{i j j k}+d_{i g k} U_{i j g k}+d_{i g j} V_{i j g j}\right)+\beta d_{i k g} Y_{i j k g}\right], }
\end{aligned}
$$

where $d_{\mathrm{ijk}}$ is the hauling distance of the $i^{\text {th }}$ dump truck from the $j^{\text {th }}$ replenishment center to the $k^{\text {th }}$ cutting field, $d_{\mathrm{ikg}}$ is the hauling distance from the $\mathrm{k}^{\text {th }}$ cutting field to the $g^{\text {th }}$ filling field, $d_{\text {igk }}$ is the hauling distance from the $g^{\text {th }}$ filling field to the $k^{\text {th }}$ cutting field, and $d_{\mathrm{igj}}$ is the hauling distance from the $g^{\text {th }}$ filling field to the $j^{\text {th }}$ replenishment center. $\alpha$ and $\beta$ are the average fuel consumption per unit distance of each dump truck at no load and full load, respectively. $X_{\mathrm{ijjk}}, Y_{\mathrm{ijkg}}, U_{\mathrm{ijgk}}$, and $V_{\mathrm{ijgj}}$ are binary decision variables.

Equation (2) is the objective function that consists of two parts. The first part is the total fuel consumption of all dump trucks at no load. To be specific, $\alpha d_{\mathrm{ijk}} X_{\mathrm{ijjk}}$ indicates the fuel consumption of the $i^{\text {th }}$ dump truck at the $j^{\text {th }}$ replenishment center dispatched from the $j^{\text {th }}$ replenishment center to the $k^{\text {th }}$ cutting field, $\alpha d_{\text {igk }} U_{\text {ijgk }}$ is the fuel consumption upon traveling from the $g^{\text {th }}$ filling field back to the $k^{\text {th }}$ cutting field at no load, and $\alpha d_{\text {igj }} V_{\text {iggj }}$ represents the fuel consumption coming from the $g^{\text {th }}{ }^{\text {filling field back to the } j^{\text {th }}}$ replenishment center at no load. The second part is the total fuel consumption of all dump trucks at full load, specifically referring to the sum fuel consumption hauling from the $k^{\text {th }}$ cutting field to the $g^{\text {th }}$ filling field.

In addition, the objective function in (1) should be subjected to the following constraints:

$$
\begin{aligned}
& \sum_{i \in I_{j}} \sum_{k \in K} X_{i j j k} \leq a_{j}, \forall i \in I_{j}, \forall j \in J, \forall k \in K, \\
& \sum_{j \in J} \sum_{i \in I_{j}} \sum_{g \in G}\left(X_{i j j k}+U_{i j g k}\right) \geq b_{k}, \quad \forall i \in I_{j}, \forall j \in J, \forall k \in K, \forall g \in G, \\
& \sum_{j \in J} \sum_{i \in I_{j}} \sum_{k \in K} Y_{i j k g} \geq c_{g}, \quad \forall i \in I_{j}, \forall j \in J, \forall k \in K, \forall g \in G, \\
& \sum_{k \in K} \sum_{g \in G}\left[\left(d_{i j k}+d_{i g k}+d_{i k j}\right) \alpha+d_{i k g} \beta\right] \leq l_{i j}, \quad \forall i \in I_{j}, \forall j \in J, \forall k \in K, \forall g \in G,
\end{aligned}
$$




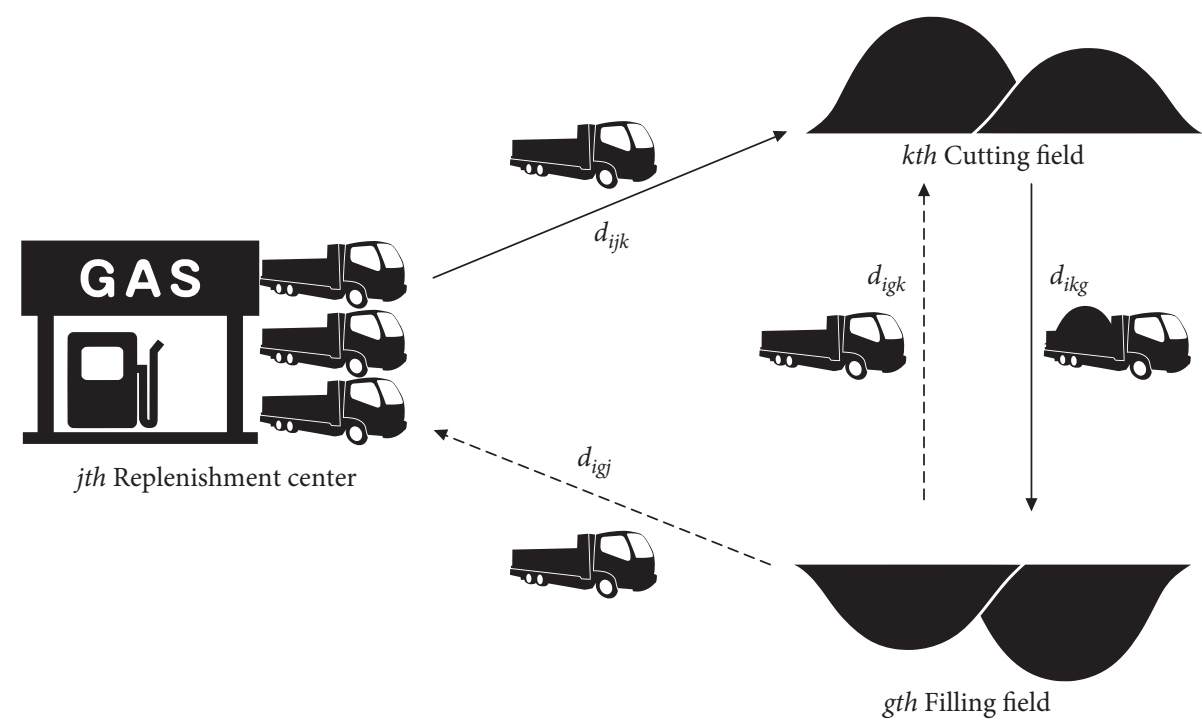

FIGURE 2: Schematic diagram of earthwork allocation (the dash lines indicate that the trucks have two options depending on their mileage limitation. They can either return to a replenishment center or head to a cutting field to reload).

$$
\begin{aligned}
& \sum_{k \in K} b_{k} \geq \sum_{g \in G} c_{g}, \quad \forall k \in K, \forall g \in G, \\
& X_{i j j k} \in\{0,1\}, \quad \forall i \in I_{j}, \forall j \in J, \forall k \in K, \\
& Y_{i j k g} \in\{0,1\}, \quad \forall i \in I_{j}, \forall j \in J, \forall k \in K, \forall g \in G, \\
& U_{i j g k} \in\{0,1\}, \quad \forall i \in I_{j}, \forall j \in J, \forall k \in K, \forall g \in G, \\
& V_{i j g j} \in\{0,1\}, \quad \forall i \in I_{j}, \forall j \in J, \forall g \in G,
\end{aligned}
$$

where $a_{j}$ is the total number of available dump trucks at the $j^{\text {th }}$ replenishment center. (3) represents that the dispatched dump trucks from each replenishment center should not exceed the maximum number of available dump trucks parked in each replenishment center. Equations (4) and (5) determine that the number of dump trucks sent to each cutting field and each filling field should satisfy the earthwork hauling need. Equation (6) indicates that the maximum hauling distance of each dump truck is constrained by its own maximum fuel capacity. Equation (7) indicates that the earth volume in all cutting fields must not be less than that in all filling fields, otherwise, the filling need will not be satisfied. Equations (8) to (11) are the decision variables to control the hauling path of each dump truck.

\section{Adaptive Genetic Algorithm}

The proposed earthwork allocation problem can be regarded as an MD-TEVRP, which is a many (dump trucks in the replenishment centers)-to-many (filling fields) matching problem, considering the transfer stations (cutting fields). The MD-TEVRP is an NP-hard question [41], and thus, this paper proposed an adaptive genetic algorithm to determine the optimal solution.
The genetic algorithm is a heuristic algorithm that is based on the "Survival of the Fittest" and "Natural Selection" theories. Figure 3 depicts the process and technique by which randomly created individuals compete with one another and form new generations using self-adaptive crossover and mutation strategies. When the system converges to a stable solution in the final phase, it signifies that the optimal solution has been discovered.

3.1. Generation of Initial Population. Based on the dynamic planning theory, the Floyd algorithm is used to calculate the shortest distance between the arbitrary points $i$ and $j$ in the original spatial weight matrix [42]. The Floyd algorithm seeks a third point $k$ between the points $i$ and $j$ by comparing the distances from $i$ to $j$ directly and from $i$ to $j$ via $k$. If the latter distance is shorter, the path $i-k-j$ is updated as the shortest distance between the points $i$ and $j$. Therefore, the recursive process of the Floyd algorithm can be expressed as follows:

$$
d_{i j}^{k}=\min \left(d_{i j}^{k-1}, d_{i k}^{k-1}+d_{j k}^{k-1}\right)
$$

By deriving the shortest distance between each point via (4), the next step is to find the optimal path for the many-to- 


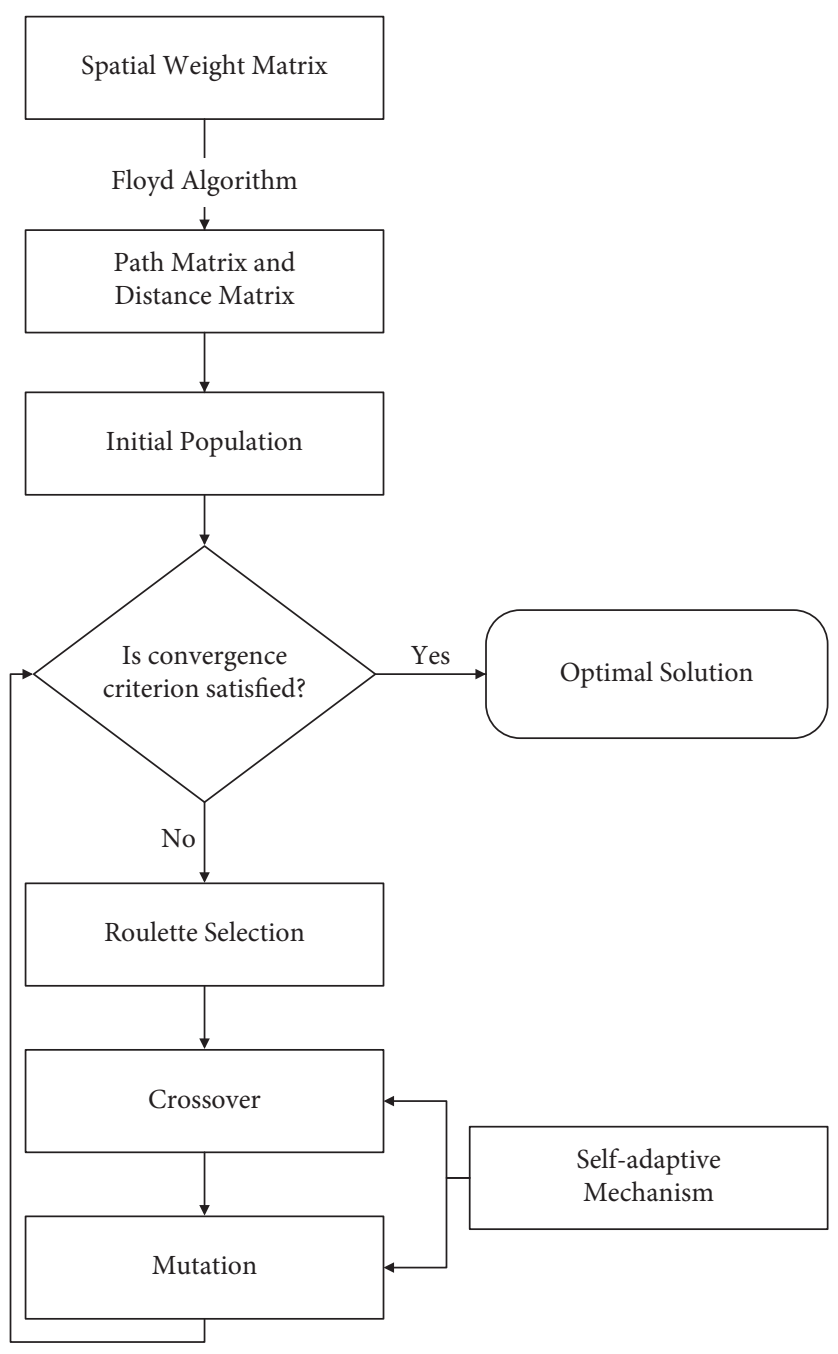

FIgURE 3: Flow chart of the adaptive genetic algorithm.

many problem described in Section 2. As depicted in Figure 3 , the next step is to determine the coding of the initial population.

Assume that there are $N$ units (chromosomes) in each generation, and each chromosome contains two parts: one is the feasible solution, while the other is the fitness value. Therefore, the information of a chromosome can be stored in a $1 \times 2$ Cell Array. According to the proposed model, the coding for the first element in the array can be designed as a $\left(\sum_{g \in G} c_{g}\right) \times 7$ matrix to store the information of a feasible solution. The formation of this matrix is generated by our proposed many-to-many algorithm, as seen in Table 1 .

To be more specific, if the dump truck was assigned a one-way path because of its mileage limit, the one-way path solution can be expressed as a $1 \times 7$ matrix that contains the following information (see Table 2):

Similarly, a multiway path viable solution can be expressed in a $x \times 7$ matrix shown in Table 3 . It is noticeable that the final retuning replenishment center should be the same as the departure one.

The second element of the array records the fitness value of each chromosome, which stores the sum of the total fuel consumption of all dispatched trucks in the corresponding feasible solution.

3.2. Roulette Select. Roulette selection is to determine some better individuals from the paternal chromosome based on the fitness value associated with the paternal chromosome. The smaller the fitness value, the more likely the corresponding chromosome is to be inherited. In addition, the elite strategy was adopted for the offspring generated after the above random operation, in which the best feasible solution of the parent gene was retained and the worst feasible solution of the offspring was replaced by the best feasible solution of the parent. The fitness value is defined as follows: 
TABLE 1: Algorithm for generating initial population.

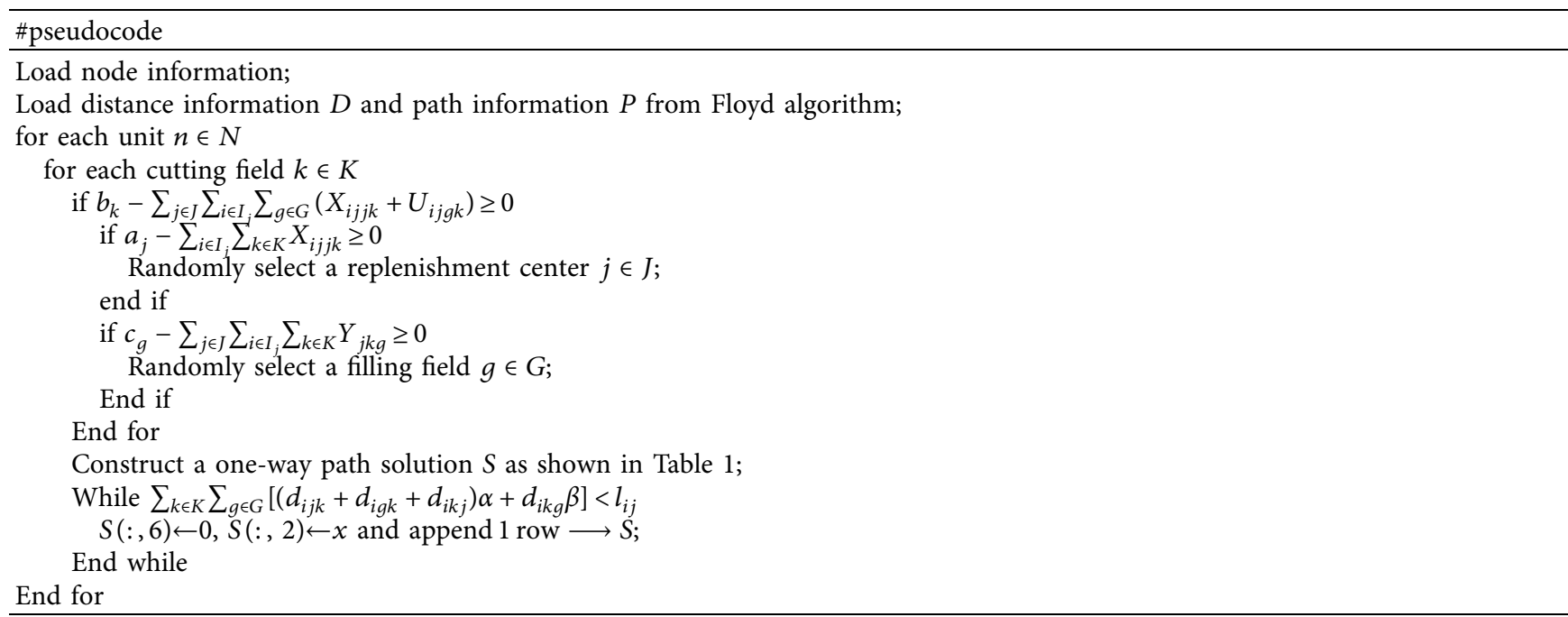

TABLe 2: An example of a one-way path feasible solution.

\begin{tabular}{|c|c|c|c|c|c|c|}
\hline 1 & 0 & 2 & 4 & 6 & 8 & 1 \\
\hline $\begin{array}{l}\text { Indexing the } \\
\text { number of } \\
\text { dispatched dump } \\
\text { trucks }\end{array}$ & $\begin{array}{c}\text { Indexing it is a } \\
\text { one-way path } \\
\text { solution }\end{array}$ & $\begin{array}{l}\text { The serial number of } \\
\text { the departure } \\
\text { replenishment center }\end{array}$ & $\begin{array}{l}\text { The serial } \\
\text { number of the } \\
\text { cutting field } \\
\text { arrived at }\end{array}$ & $\begin{array}{l}\text { The serial } \\
\text { number of the } \\
\text { filling field } \\
\text { reached }\end{array}$ & $\begin{array}{l}\text { The serial number of } \\
\text { the returned } \\
\text { replenishment center }\end{array}$ & $\begin{array}{c}\text { The total distance } \\
\text { the truck travels } \\
\text { in the current } \\
\text { dispatch }\end{array}$ \\
\hline
\end{tabular}

TABLe 3: An example of a multiway path feasible solution.

\begin{tabular}{|c|c|c|c|c|c|c|}
\hline $\begin{array}{l}\text { Indexing the } \\
\text { number of } \\
\text { dispatched } \\
\text { dump trucks }\end{array}$ & $\begin{array}{l}\text { Indexing how } \\
\text { many runs the } \\
\text { current truck } \\
\text { travels }\end{array}$ & $\begin{array}{l}\text { The serial number of } \\
\text { the departure } \\
\text { replenishment center }\end{array}$ & $\begin{array}{l}\text { The serial } \\
\text { number of the } \\
\text { cutting field } \\
\text { arrived at }\end{array}$ & $\begin{array}{l}\text { The serial } \\
\text { number of the } \\
\text { filling field } \\
\text { reached }\end{array}$ & $\begin{array}{l}0 \text { if the dump trucks can } \\
\text { continue shipment, otherwise } \\
\text { indexing the serial number of } \\
\text { the returned replenishment } \\
\text { center }\end{array}$ & $\begin{array}{l}\text { The distance } \\
\text { the truck } \\
\text { travels in } \\
\text { each run }\end{array}$ \\
\hline 1 & 1 & 2 & 5 & 6 & 0 & 5 \\
\hline 1 & 2 & 4 & 7 & 9 & 0 & 10 \\
\hline $\begin{array}{l}\cdots \\
1\end{array}$ & $x$ & 3 & 2 & 5 & 2 & 14 \\
\hline 2 & 1 & 2 & 5 & 6 & 0 & 5 \\
\hline 2 & 2 & 4 & 7 & 9 & 0 & 10 \\
\hline $\begin{array}{l}\cdots \\
2\end{array}$ & $x$ & 3 & 2 & 5 & 2 & 14 \\
\hline
\end{tabular}

$$
f_{n}=\frac{1}{\sum_{j \in J} \sum_{i \in I_{j}} \sum_{k \in K} \sum_{g \in G}\left[\alpha\left(d_{\mathrm{ijk}} X_{\mathrm{ijjk}}+d_{\mathrm{igk}} U_{\mathrm{ijgk}}+d_{\mathrm{igj}} V_{\mathrm{ijgj}}\right)+\beta d_{\mathrm{ikg}} Y_{\mathrm{ijkg}}\right]}, \quad n \in N
$$

The probability of selecting each unit from the population is calculated as

$$
p_{n}=\frac{f_{n}}{\sum_{n \in N} f_{n}} .
$$

3.3. Crossover. In this model, the individual pairs of chromosomes can intersect with each other according to the crossover rate defined in (8), i.e., a certain rate of individual pairs can exchange their cutting fields and recalculate their overall mileage and fitness value thereafter. The crossover rate is self-adaptive according to the proportion $p$ of the ratio of current optimal individuals to the whole population size. $\omega$ is the allowable peak crossover rate, and thus, $C R \in[0, \omega] \forall p \in(0,1]$.

$$
C R=\omega \log _{50}(50 p) .
$$

Specifically, if the crossover rate is satisfied, the $n^{\text {th }}$ unit will swap its cutting field with the $(n+N / 2)^{t h}$ unit. The algorithm is presented in Table 4. 
TABLE 4: Algorithm for crossover.
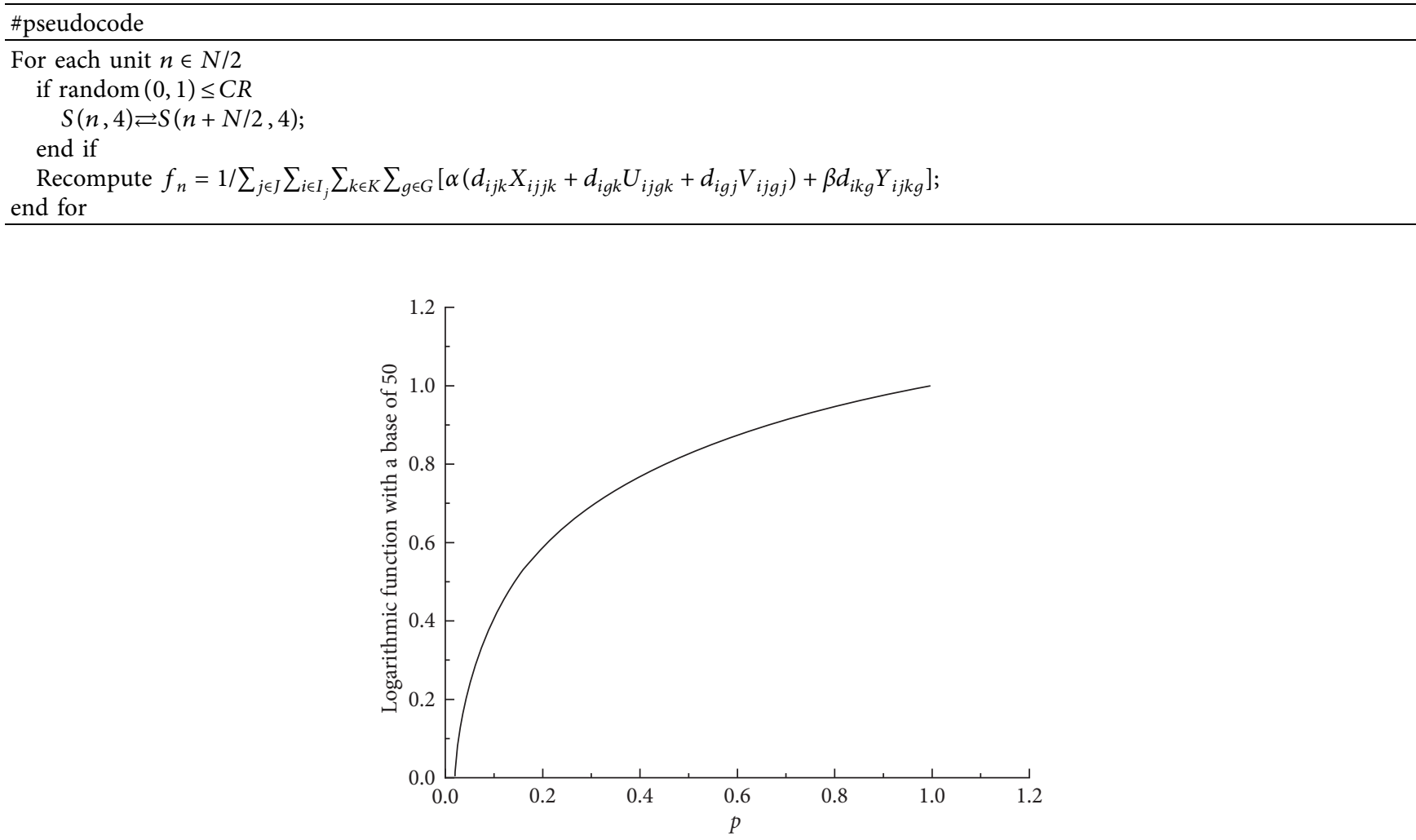

FIGURE 4: Logarithmic functions with a base of 50 .

TABLE 5: Algorithm for mutation.

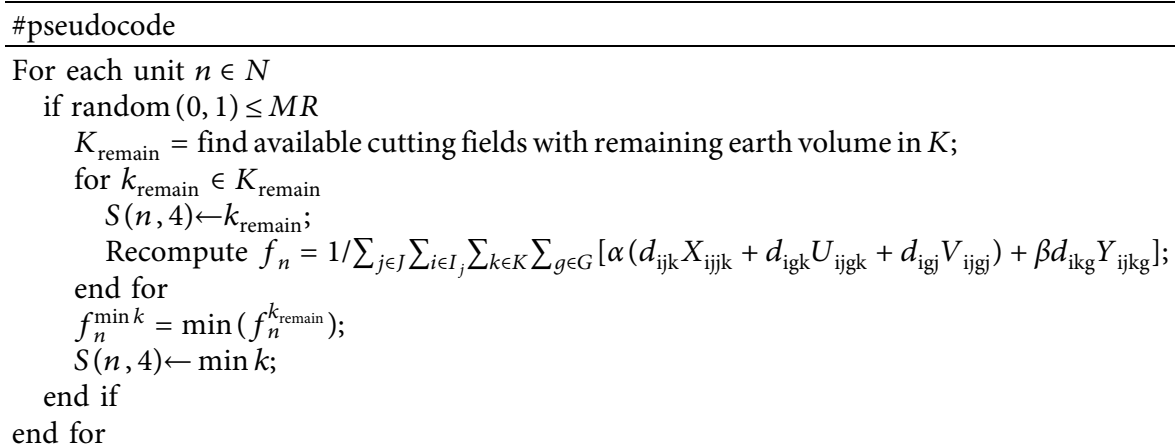

Equation (8) is an increasing logarithmic function subjected to the proportion of the current optimal individuals. The shape of (8) is demonstrated in Figure 4. As indicated, as the number of optimal individual increases, the crossover rate will rise to increase the population diversity to avoid premature problem. It is noticeable that when $p$ is larger than 0.02 , the crossover rate and the mutation rate will become positive. $p$ is the proportion of the current optimal individuals to the whole population. In this case, we assume that only when the proportion of optimal individuals is larger than $2 \%$, the self-adaptive mechanism will work and start to manipulate the diversity of population. Otherwise, the algorithm will let the nature take its course.
3.4. Mutation. In the mutation stage, this paper mainly carries out the variation operations on the fourth element (cutting fields) of the first array. Specifically, this paper will replace the cutting field with another available one with the remaining earth volume required to be transported, which can achieve a shorter hauling distance from the replenishment centers to the filling fields on this single run. Therefore, it is necessary to ensure that the amount of earthwork in the cutting fields is not less than that in the filling fields when modeling, so that it can provide redundant earth volume in the cutting fields for variation. After mutation, the path length traveled by the dump trucks and the corresponding fitness value of the entire feasible solution will be updated again. The mutation rate is 


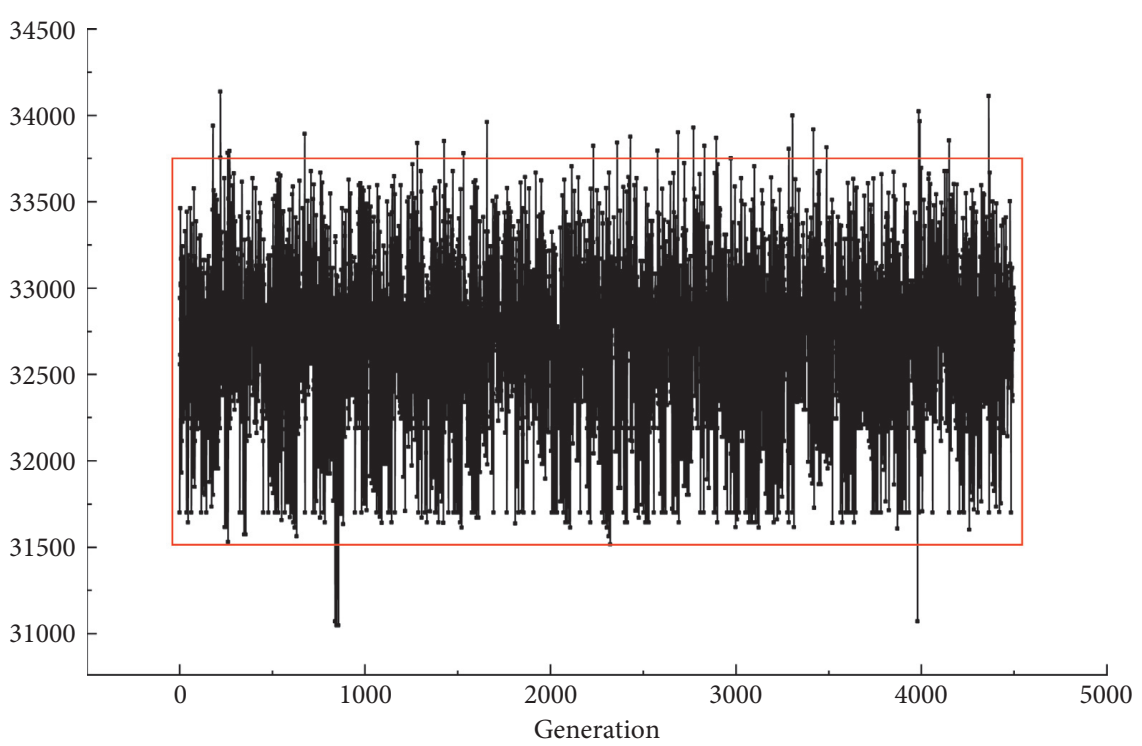

FIGURE 5: High diversity of optimal solutions at each generation.

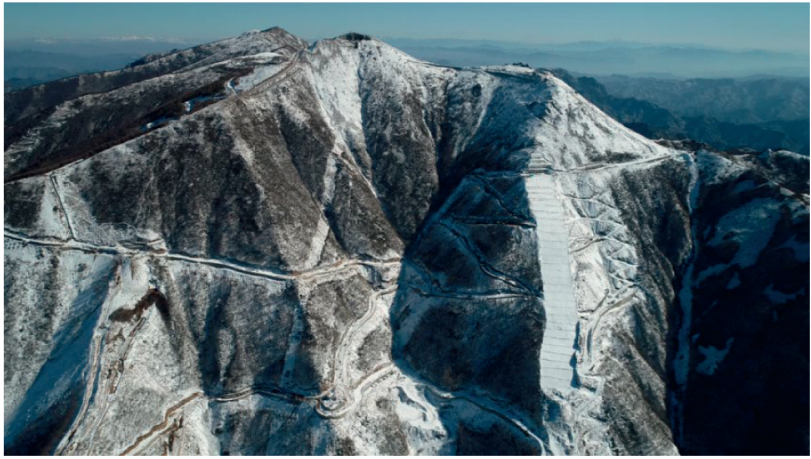

(a)

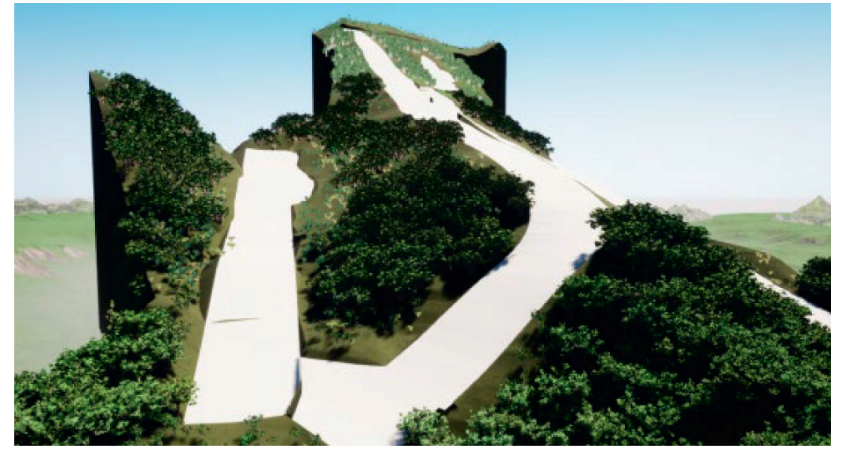

(c)

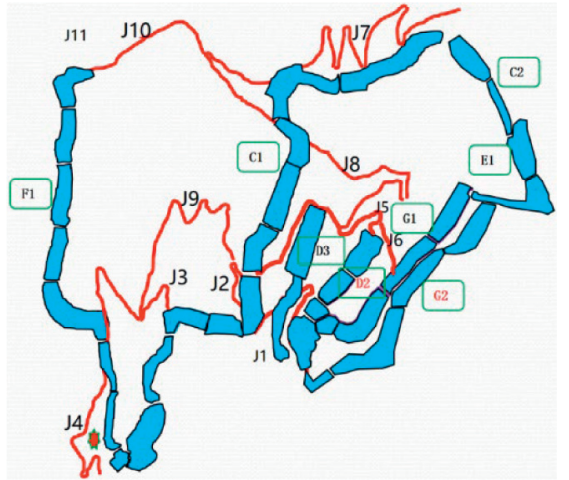

(b)

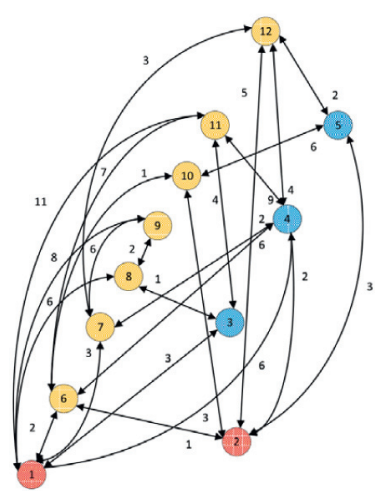

(d)

FIGURE 6: Skiing courses of the Beijing Winter Olympic Games Skiing Center in Yanqing District. (a) Real map of the skiing courses. (b) Distribution plan of the skiing courses. (c) BIM map of the G1 and D2 skiing courses. (d) Schematic diagram of the transportation network between the two depots, G1 and D2 skiing courses.

also controlled by a self-adaptive mechanism as (16), where $\chi$ is the maximum mutation rate, which ensures $M R \in[0, \chi] \forall p \in(0,1]$.

$$
M R=\chi \log _{50}(50 p) .
$$

As displayed in Table 5, the mutation algorithm aims to find the best cutting field to achieve a lower fitness value for 


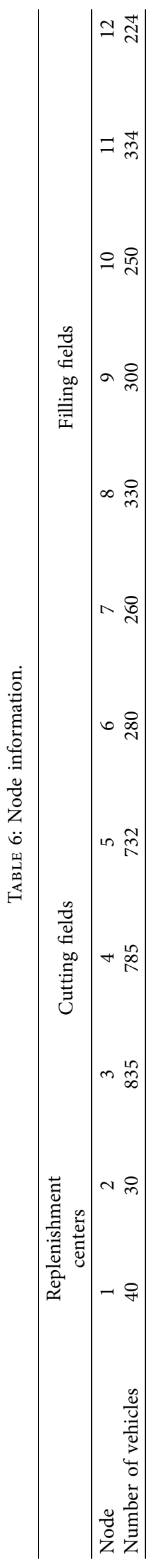


TABle 7: The spatial weight matrix.

\begin{tabular}{|c|c|c|c|c|c|c|c|c|c|c|c|c|c|}
\hline & \multicolumn{13}{|c|}{ Destinations } \\
\hline & 0 & - & 3 & 6 & - & 2 & 3 & 6 & 8 & - & 11 & - & 0 \\
\hline & - & 0 & - & 2 & 3 & 1 & - & - & - & 3 & - & 5 & - \\
\hline & 3 & - & 0 & - & - & - & - & 1 & - & - & 4 & - & 3 \\
\hline & 6 & 2 & - & 0 & - & 6 & 2 & - & - & - & 9 & 4 & 6 \\
\hline & - & 3 & - & - & 0 & - & - & - & - & 6 & - & 2 & - \\
\hline & 2 & 1 & - & 6 & - & 0 & - & - & - & 1 & 7 & - & 2 \\
\hline \multirow[t]{7}{*}{ Origins } & 3 & - & - & 2 & - & - & 0 & - & 6 & - & - & 3 & 3 \\
\hline & 6 & - & 1 & - & - & - & - & 0 & 2 & - & - & - & 6 \\
\hline & 8 & - & - & - & - & - & 6 & 2 & 0 & - & - & - & 8 \\
\hline & - & 3 & - & - & 6 & 1 & - & - & - & 0 & - & - & - \\
\hline & 11 & - & 4 & 9 & - & 7 & - & - & - & - & 0 & - & 11 \\
\hline & - & 5 & - & 4 & 2 & - & 3 & - & - & - & - & 0 & - \\
\hline & 0 & - & 3 & 6 & - & 2 & 3 & 6 & 8 & - & 11 & - & 0 \\
\hline
\end{tabular}

each run. Once the mutation rate is satisfied, the algorithm will find all available cutting fields that can replace the original one and select the one with the least fitness value among all the alternatives.

The adaptive mechanism in the mutation stage is similar to that in the crossover stage, which aims to enlarge the diversity of the population and prevent a premature problem. As shown in Figure 5, during 4500 iterations, the optimal solution at each generation oscillates up and down greatly, ranging from 31,500 to 33,750 , which means a high divergence population is maintained by this self-adaptive mechanism to avoid a premature problem. This adaptive mechanism provides more possibility to seek better solutions by jumping out local convergence.

3.5. Recursive Optimization. A better solution with the lower fitness value can be obtained by repeating sections 3.2 to 3.4 and iteratively updating the chromosomal information of each generation of the population until meeting the following convergence criterion:

$$
\text { number of iterations }=\max \left(500, n_{s}\right),
$$

where $n_{s}$ is the number of iterations when the optimal solution remains unchanged for over 50 iterations.

\section{Validation of the Proposed Algorithm}

To validate the proposed algorithm, an earthwork allocation project on the G1 and D2 skiing courses of the Beijing Winter Olympic Games Skiing Center in 2022 is used. The schematic diagram of the original transportation network is shown in Figure 6, and the initial conditions of this case study are listed as follows:

(1) Overall excavation volume: $2352 \mathrm{~m}^{3}$

(2) Overall filling volume: $1978 \mathrm{~m}^{3}$

(3) Maximum carrying capacity of each dump truck: $10 \mathrm{~m}^{3}$

(4) The transportation fuel consumption of empty load is $0.1 \mathrm{~L} / \mathrm{km}$
(5) The transportation fuel consumption of full loaded is $0.2 \mathrm{~L} / \mathrm{km}$

(6) The maximum capacity of fuel tank: $100 \mathrm{~L}$

(7) Number of cutting fields: 3

(8) Number of filling fields: 7

(9) Number of replenishment centers: 2

The node information is listed in Table 6 . The number of dump trucks in Table 6 provides the meanings, subject to the locations, respectively, as follows:

(1) Number of dump trucks each replenishment center can provide

(2) Number of dump trucks needed to transport all earth volume away from the cutting fields

(3) Number of dump trucks needed to transport the required earth volume to the filling fields

According to the distance information read from Figure 3 , the spatial weight matrix can be constructed as Table 7 .

According to equation (12), the distance information matrix and the path information matrix can be derived (see Tables 8 and 9).

The overall demand of all filling areas is 1978, and thus, the final optimal solution is a $1978 \times 7$ matrix. Each row represents the path information of a single run. Table 10 demonstrates the results of the optimal solution for the last 20 rows. It can be seen that 2 dump trucks are dispatched for multiple deliveries (e.g., the $63^{\text {rd }}$ dump truck has been assigned to carry out 12 transportation tasks from 1959 to 1970). Therefore, the optimal path can be read assisted by Table 9 generated from Floyd Algorithm. For instance, the $1959^{\text {th }}$ run travels from 1-4-11 as indicated in Table 10; however, the real hauling path from 1 to 11 is $1-6-2-4-11$ by reading the path information matrix in Table 9. It is worth noting that 64 dump trucks are used to carry out the earthwork allocation task and achieve minimal fuel consumption so far.

Meanwhile, Figure 7 is the iterative optimizing process. The iteration operates 500 times in total and converges at the $440^{\text {th }}$ generation. The final optimal fuel consumption is $31352 \mathrm{~L}$. 
Table 8: The Floyd distance information matrix $(1=5 \mathrm{~km})$.

\begin{tabular}{|c|c|c|c|c|c|c|c|c|c|c|c|c|c|}
\hline \multirow{2}{*}{ Node } & \multirow[t]{2}{*}{ Node } & \multicolumn{12}{|c|}{ Destinations } \\
\hline & & 1 & 2 & 3 & 4 & 5 & 6 & 7 & 8 & 9 & 10 & 11 & 12 \\
\hline \multirow{12}{*}{ Origins } & 1 & 0 & 3 & 3 & 5 & 6 & 2 & 3 & 4 & 6 & 3 & 7 & 6 \\
\hline & 2 & 3 & 0 & 6 & 2 & 3 & 1 & 4 & 7 & 9 & 2 & 8 & 5 \\
\hline & 3 & 3 & 6 & 0 & 8 & 9 & 5 & 6 & 1 & 3 & 6 & 4 & 9 \\
\hline & 4 & 5 & 2 & 8 & 0 & 5 & 3 & 2 & 9 & 8 & 4 & 9 & 4 \\
\hline & 5 & 6 & 3 & 9 & 5 & 0 & 4 & 5 & 10 & 11 & 5 & 11 & 2 \\
\hline & 6 & 2 & 1 & 5 & 3 & 4 & 0 & 5 & 6 & 8 & 1 & 7 & 6 \\
\hline & 7 & 3 & 4 & 6 & 2 & 5 & 5 & 0 & 7 & 6 & 6 & 10 & 3 \\
\hline & 8 & 4 & 7 & 1 & 9 & 10 & 6 & 7 & 0 & 2 & 7 & 5 & 10 \\
\hline & 9 & 6 & 9 & 3 & 8 & 11 & 8 & 6 & 2 & 0 & 9 & 7 & 9 \\
\hline & 10 & 3 & 2 & 6 & 4 & 5 & 1 & 6 & 7 & 9 & 0 & 8 & 7 \\
\hline & 11 & 7 & 8 & 4 & 9 & 11 & 7 & 10 & 5 & 7 & 8 & 0 & 13 \\
\hline & 12 & 6 & 5 & 9 & 4 & 2 & 6 & 3 & 10 & 9 & 7 & 13 & 0 \\
\hline
\end{tabular}

Table 9: The Floyd path information matrix.

\begin{tabular}{|c|c|c|c|c|c|c|c|c|c|c|c|c|c|}
\hline \multirow{2}{*}{ Node } & \multirow[t]{2}{*}{ Node } & \multicolumn{12}{|c|}{ Destinations } \\
\hline & & 1 & 2 & 3 & 4 & 5 & 6 & 7 & 8 & 9 & 10 & 11 & 12 \\
\hline \multirow{12}{*}{ Origins } & 1 & 1 & 6 & 3 & 6 & 6 & 6 & 7 & 3 & 3 & 6 & 3 & 7 \\
\hline & 2 & 6 & 2 & 6 & 4 & 5 & 6 & 4 & 6 & 6 & 6 & 6 & 12 \\
\hline & 3 & 1 & 1 & 3 & 1 & 1 & 1 & 1 & 8 & 8 & 1 & 11 & 1 \\
\hline & 4 & 2 & 2 & 2 & 4 & 2 & 2 & 7 & 2 & 7 & 2 & 11 & 12 \\
\hline & 5 & 2 & 2 & 2 & 2 & 5 & 2 & 12 & 2 & 12 & 2 & 2 & 12 \\
\hline & 6 & 1 & 2 & 1 & 2 & 2 & 6 & 1 & 1 & 1 & 10 & 11 & 2 \\
\hline & 7 & 1 & 4 & 1 & 4 & 12 & 1 & 7 & 1 & 9 & 1 & 1 & 12 \\
\hline & 8 & 3 & 3 & 3 & 3 & 3 & 3 & 3 & 8 & 9 & 3 & 3 & 3 \\
\hline & 9 & 8 & 8 & 8 & 7 & 7 & 8 & 7 & 8 & 9 & 8 & 8 & 7 \\
\hline & 10 & 6 & 6 & 6 & 6 & 6 & 6 & 6 & 6 & 6 & 10 & 6 & 6 \\
\hline & 11 & 3 & 6 & 3 & 4 & 6 & 6 & 3 & 3 & 3 & 6 & 11 & 4 \\
\hline & 12 & 7 & 2 & 7 & 4 & 5 & 2 & 7 & 7 & 7 & 2 & 4 & 12 \\
\hline
\end{tabular}

TABLE 10: Optimal solution of the last 20 rows.

\begin{tabular}{|c|c|c|c|c|c|c|}
\hline $\begin{array}{l}\text { Indexing the } \\
\text { number of } \\
\text { dispatched } \\
\text { dump trucks }\end{array}$ & $\begin{array}{l}\text { Indexing how } \\
\text { many runs of } \\
\text { current truck } \\
\text { travels }\end{array}$ & $\begin{array}{l}\text { The serial number of } \\
\text { the departure } \\
\text { replenishment center }\end{array}$ & $\begin{array}{l}\text { The serial } \\
\text { number of the } \\
\text { cutting field } \\
\text { arrived at }\end{array}$ & $\begin{array}{l}\text { The serial } \\
\text { number of the } \\
\text { filling field } \\
\text { reached }\end{array}$ & $\begin{array}{l}0 \text { if the dump trucks can } \\
\text { continue shipment, otherwise } \\
\text { indexing the serial number of } \\
\text { the returned replenishment } \\
\text { center }\end{array}$ & $\begin{array}{l}\text { The distance } \\
\text { the truck } \\
\text { travels in } \\
\text { each run }\end{array}$ \\
\hline 63 & 1959 & 1 & 4 & 11 & 0 & 14 \\
\hline 63 & 1960 & 11 & 4 & 9 & 0 & 17 \\
\hline 63 & 1961 & 9 & 4 & 9 & 0 & 16 \\
\hline 63 & 1962 & 9 & 4 & 9 & 0 & 16 \\
\hline 63 & 1963 & 9 & 4 & 9 & 0 & 16 \\
\hline 63 & 1964 & 9 & 4 & 9 & 0 & 16 \\
\hline 63 & 1965 & 9 & 4 & 9 & 0 & 16 \\
\hline 63 & 1966 & 9 & 4 & 9 & 0 & 16 \\
\hline 63 & 1967 & 9 & 4 & 9 & 0 & 16 \\
\hline 63 & 1968 & 9 & 4 & 9 & 0 & 16 \\
\hline 63 & 1969 & 9 & 4 & 9 & 0 & 16 \\
\hline 63 & 1970 & 9 & 4 & 9 & 1 & 22 \\
\hline 64 & 1971 & 1 & 4 & 9 & 0 & 13 \\
\hline 64 & 1972 & 9 & 5 & 9 & 0 & 22 \\
\hline 64 & 1973 & 9 & 5 & 9 & 0 & 22 \\
\hline 64 & 1974 & 9 & 5 & 9 & 0 & 22 \\
\hline 64 & 1975 & 9 & 5 & 9 & 0 & 22 \\
\hline 64 & 1976 & 9 & 5 & 9 & 0 & 22 \\
\hline 64 & 1977 & 9 & 5 & 9 & 0 & 22 \\
\hline 64 & 1978 & 9 & 4 & 9 & 1 & 22 \\
\hline
\end{tabular}




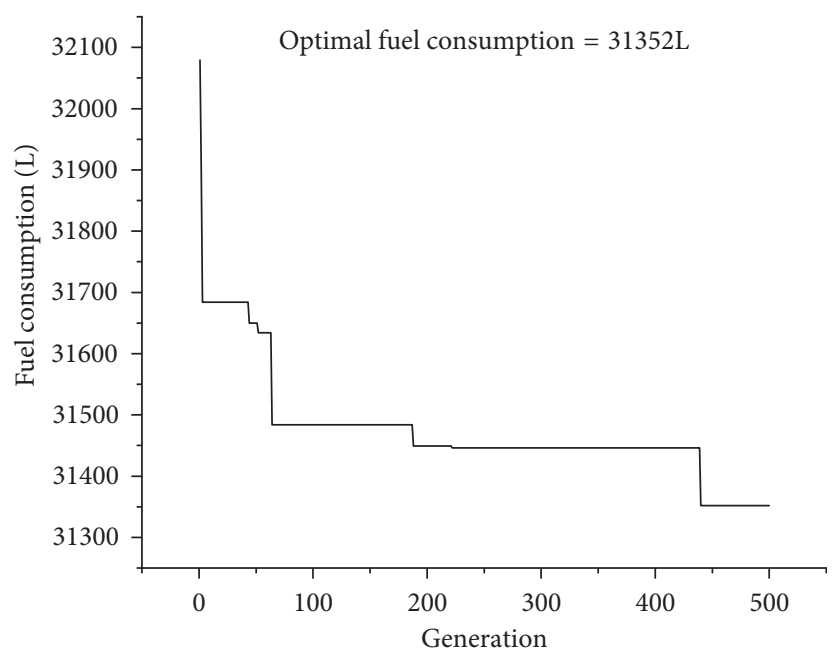

FIGURE 7: Recursive optimizing process of earthwork allocation.

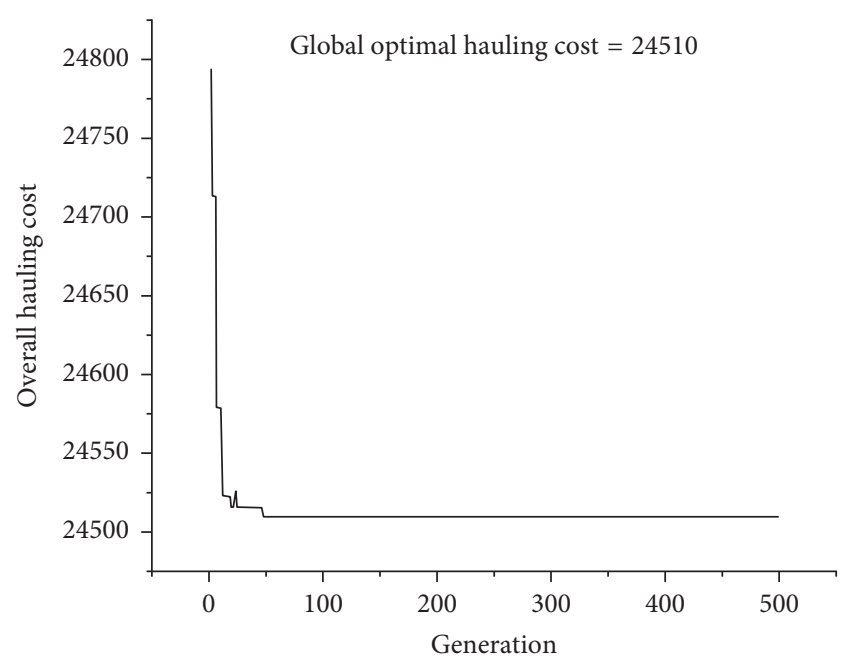

(a)

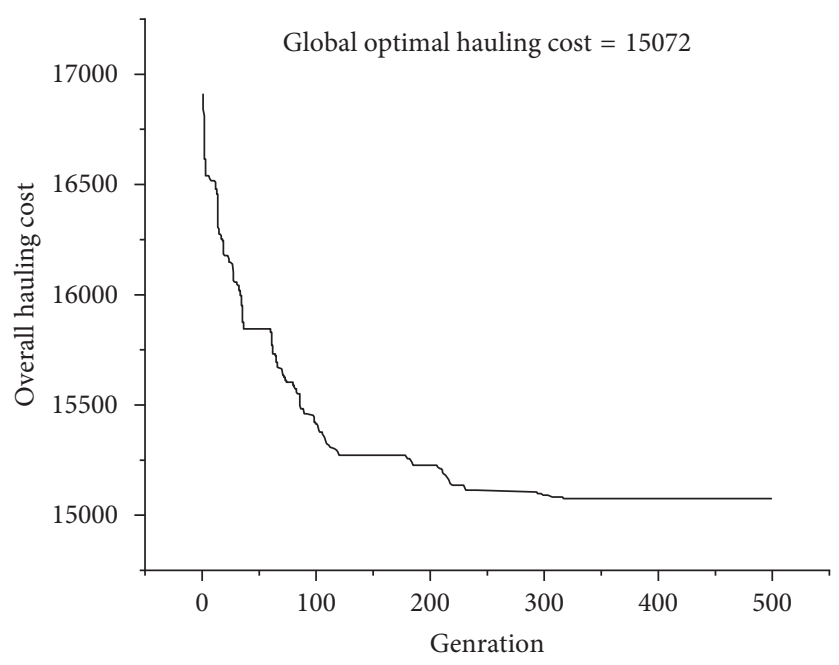

(b)

Figure 8: Comparative study between [6] and our method. (a) The former work with two-way path planning. (b) Our method with multiway path planning.

TABLE 11: Variables and explanation.

\begin{tabular}{|c|c|}
\hline Variables & Explanation \\
\hline$J$ & Number of replenishment centers \\
\hline$I_{j}$ & Number of dump trucks in the $j^{\text {th }}$ replenishment center \\
\hline$K$ & Number of cutting fields \\
\hline G & Number of filling fields \\
\hline$d_{\mathrm{ijk}}$ & The hauling distance of the $i^{\text {th }}$ dump truck from the $j^{\text {th }}$ replenishment center to the $k^{\text {th }}$ cutting field \\
\hline$d_{\mathrm{ikg}}$ & The hauling distance of the $i^{\text {th }}$ dump truck from the $k^{\text {th }}$ cutting field to the $g^{\text {th }}$ filling field \\
\hline$d_{\text {igk }}$ & The hauling distance of the $i^{\text {th }}$ dump truck from the $g^{\text {th }}$ filling field to the $k^{\text {th }}$ cutting field \\
\hline$d_{\mathrm{igj}}$ & The hauling distance of the $i^{\text {th }}$ dump truck from the $g^{\text {th }}$ filling field to the $j^{\text {th }}$ replenishment center \\
\hline$\alpha$ & The average fuel consumption per unit distance of each dump truck at no load \\
\hline$\beta$ & The average fuel consumption per unit distance of each dump truck at full load \\
\hline$X_{\mathrm{ijjk}}$ & $\begin{array}{c}\text { Binary decision variable: whether the } i^{\text {th }} \text { dump truck at the } j^{\text {th }} \text { replenishment center travels from the } j^{\text {th }} \text { replenishment center to } \\
\text { the } k^{\text {th }} \text { cutting field }\end{array}$ \\
\hline$Y_{\mathrm{ijkg}}$ & $\begin{array}{c}\text { Binary decision variable: whether the } i^{\text {th }} \text { dump truck at the } j^{\text {th }} \text { replenishment center travels from the } k^{\text {th }} \text { cutting field to the } g^{\text {th }} \\
\text { filling field }\end{array}$ \\
\hline$U_{\mathrm{ijgk}}$ & $\begin{array}{c}\text { Binary decision variable: whether the } i^{\text {th }} \text { dump truck at the } j^{\text {th }} \text { replenishment center travels from the } g^{\text {th }} \text { filling field to the } k^{\text {th }} \\
\text { cutting field }\end{array}$ \\
\hline
\end{tabular}


TABLE 11: Continued.

\begin{tabular}{|c|c|}
\hline Variables & Explanation \\
\hline$V_{\text {ijgj }}$ & $\begin{array}{c}\text { Binary decision variable: whether the } i^{\text {th }} \text { dump truck at the } j^{\text {th }} \text { replenishment center travels from the } g^{\text {th }} \text { filling field to the } j^{\text {th }} \\
\text { replenishment center }\end{array}$ \\
\hline$a_{j}$ & Total number of available dump trucks at the $j^{\text {th }}$ replenishment center \\
\hline$b_{k}$ & Total number of fully loaded dump trucks needed to haul all earthwork in the $k^{\text {th }}$ cutting field \\
\hline$c_{g}$ & Total number of fully loaded dump trucks needed to fill the $g^{\text {th }}$ filling field \\
\hline$l_{i j}$ & The maximum fuel capacity of the $i^{\text {th }}$ dump truck at the $j^{\text {th }}$ replenishment center \\
\hline$N$ & Population size \\
\hline$f_{n}$ & The fitness value of the $\mathrm{n}^{\text {th }}$ unit \\
\hline$p_{n}$ & The probability of selecting each unit from the population \\
\hline$\omega$ & The allowable peak crossover rate \\
\hline$C R$ & The crossover rate \\
\hline$p$ & The ratio of current optimal individuals to the whole population size \\
\hline$x$ & The maximum mutation rate \\
\hline$M R$ & The mutation rate \\
\hline$n_{s}$ & The number of iterations when the optimal solution remains unchanged for over 50 iterations \\
\hline
\end{tabular}

To further validate the performance of our proposed algorithm, a comparative study has been made by comparing our method with former work in [6]. The result in Figure 8 demonstrated that our method showed a dominant advantage over the past work, and roughly, a performance boost of $38 \%$ is achieved. The global optimal hauling cost in Figure 8 is related to fuel consumption. Thus, a slight change to the algorithm is made to accord with the optimization objective.

\section{Conclusions}

This paper constructs a complex earthwork allocation pathplanning modeling based on MD-TEVRP by considering the multiple runs of dump trucks between the cutting fields and the filling fields. A well-designed genetic algorithm based on this model is proposed to achieve the following contributions:

(1) This paper provides a multiway transportation solution to a typical MD-TEVRP, which achieves many-to-many recursive pairing in earthwork allocation path planning.

(2) The proposed self-adaptive mechanism can manipulate the diversity of the generated populations to prevent the premature problem of GA and achieve a lower fitness value.

(3) The optimization method shows a dominant advantage over the past work by increasing approximately $38 \%$ of performance. The proposed method also provides guidance for the construction design of the Skiing Courses of Beijing Winter Olympic Games Skiing Center in Yanqing, Beijing.

The implication of variables is listed in Table 11.

\section{Data Availability}

The data presented in this study are available on request to the corresponding author.

\section{Conflicts of Interest}

The authors declare that they have no conflicts of interest.

\section{References}

[1] S. H. Kang, J. W. Seo, and K. G. Baik, "3D-GIS based earthwork planning system for productivity improvement," in Proceedings of the American Society of Civil Engineers Construction Research Congress 2009, pp. 151-160, Seattle, WA, USA, April 2009.

[2] Y. Ji, A. Borrmann, E. Rank, F. Seipp, and S. Ruzika, "Mathematical modeling of earthwork optimization problems," in Proceedings of the International Conference on Computing in Civil and Building Engineering (ICCCBE), Nottingham, UK, January 2010.

[3] M. Parente, P. Cortez, and A. G. Correia, "An evolutionary multi-objective optimization system for earthworks," Expert Systems with Applications, vol. 42, pp. 6674-6685, 2015.

[4] R. Burdett, E. Kozan, and R. Kenley, "Block models for improved earthwork allocation planning in linear infrastructure construction," Engineering Optimization, vol. 47, no. 3, pp. 347-369, 2015.

[5] A. M. Ahmad, "Spline technique for modeling roadway profile to minimize earthwork cost," Journal of Industrial and Management Optimization, vol. 5, no. 2, pp. 275-283, 2009.

[6] N. Deng, X. Li, and Y. Su, "Optimization of earthwork allocation path as vehicle route problem based on genetic algorithm," in Proceedings of the 2020 2nd International Conference on Civil Architecture and Energy Science (CAES 2020), Changchun, China, March 2020.

[7] K. Miao, X. Sun, and L. Li, "A roadbed earthwork allocation model based on ACO algorithm," Applied Mechanics and Materials, vol. 44-47, pp. 3483-3486, 2011.

[8] R. L. Burdett and E. Kozan, "An integrated approach for earthwork allocation, sequencing and routing," European Journal of Operational Research, vol. 238, no. 3, pp. 741-759, 2014.

[9] G. Desaulniers, J. Desrosiers, A. Erdmann, M. M. Solomon, and F. Soumis, "9. VRP with pickup and delivery," The vehicle routing problem, vol. 9, pp. 225-242, 2002.

[10] G. Kim, Y.-S. Ong, C. K. Heng, P. S. Tan, and N. A. Zhang, "City vehicle routing problem (city VRP): a review," IEEE Transactions on Intelligent Transportation Systems, vol. 16, no. 4, pp. 1654-1666, 2015.

[11] G. B. Dantzig and J. H. Ramser, "The truck dispatching problem," Management Science, vol. 6, no. 1, pp. 80-91, 1959. 
[12] E. D. Taillard, "A heuristic column generation method for the heterogeneous fleet VRP," RAIRO - Operations Research, vol. 33, no. 1, pp. 1-14, 1999.

[13] J. Holland, Adaptation in Natural and Artificial Systems: An Introductory Analysis with Application to Biology. Control And Artificial Intelligence, MIT Press, Cambridge, MA, USA, 1975.

[14] B. M. Baker and M. A. Ayechew, "A genetic algorithm for the vehicle routing problem," Computers \& Operations Research, vol. 30, no. 5, pp. 787-800, 2003.

[15] A. K. M. Masum, M. Shahjalal, F. Faruque, and I. Sarker, "Solving the vehicle routing problem using genetic algorithm," International Journal of Advanced Computer Science and Applications, vol. 2, pp. 126-131, 2011.

[16] S.-I. Hwang, J.-H. Son, and S.-H. Lee, "Development of scheduling model for earth work using genetic algorithm," KSCE Journal of Civil Engineering, vol. 18, no. 6, pp. 16181624, 2014.

[17] R. Montemanni, L. M. Gambardella, A. E. Rizzoli, and A. V. Donati, "Ant colony system for a dynamic vehicle routing problem," Journal of Combinatorial Optimization, vol. 10, no. 4, pp. 327-343, 2005.

[18] M. Reed, A. Yiannakou, and R. Evering, "An ant colony algorithm for the multi-compartment vehicle routing problem," Applied Soft Computing, vol. 15, pp. 169-176, 2014.

[19] B. Yu, Z.-Z. Yang, and J.-X. Xie, "A parallel improved ant colony optimization for multi-depot vehicle routing problem," Journal of the Operational Research Society, vol. 62, no. 1, pp. 183-188, 2011.

[20] R. Eberhart and J. Kennedy, "A new optimizer using particle swarm theory," in Proceedings of the MHS'95. Proceedings of the Sixth International Symposium on Micro Machine and Human Science, pp. 39-43, Nagoya, Japan, October 1995.

[21] Y. Marinakis, M. Marinaki, and G. Dounias, "A hybrid particle swarm optimization algorithm for the vehicle routing problem," Engineering Applications of Artificial Intelligence, vol. 23, no. 4, pp. 463-472, 2010.

[22] F. Belmecheri, C. Prins, F. Yalaoui, and L. Amodeo, "Particle swarm optimization algorithm for a vehicle routing problem with heterogeneous fleet, mixed backhauls, and time windows," Journal of Intelligent Manufacturing, vol. 24, no. 4, pp. 775-789, 2013.

[23] C. Xiutong and L. Lu, "Study on earthwork allocation method based on modified particle swarm optimization," Journal of Hydroelectric Engineering, vol. 29, pp. 68-72, 2010.

[24] M. Dorigo, "Optimization, Learning and Natural Algorithms," $\mathrm{PhD}$ Thesis, Politecnico di, Milano, Italy, 1992.

[25] I. H. Osman, "Metastrategy simulated annealing and tabu search algorithms for the vehicle routing problem," Annals of Operations Research, vol. 41, no. 4, pp. 421-451, 1993.

[26] L. Wei, Z. Zhang, D. Zhang, and S. C. H. Leung, "A simulated annealing algorithm for the capacitated vehicle routing problem with two-dimensional loading constraints," European Journal of Operational Research, vol. 265, no. 3, pp. 843-859, 2018.

[27] F. Glover, "Tabu search-Part I," ORSA Journal on Computing, vol. 1, no. 3, pp. 190-206, 1989.

[28] G. Barbarosoglu and D. Ozgur, "A tabu search algorithm for the vehicle routing problem," Computers \& Operations Research, vol. 26, no. 3, pp. 255-270, 1999.

[29] D. Schermer, M. Moeini, and O. Wendt, "A hybrid VNS/Tabu search algorithm for solving the vehicle routing problem with drones and en route operations," Computers \& Operations Research, vol. 109, pp. 134-158, 2019.
[30] X. Li and M. Yin, "Hybrid differential evolution with biogeography-based optimization for design of a reconfigurable antenna array with discrete phase shifters," International Journal of Antennas and Propagation, vol. 2011, Article ID 685629, 12 pages, 2011.

[31] Y. Xiao, J. Jiao, J. Pei, K. Zhou, and X. Yang, “A multi-strategy improved ant colony algorithm for solving traveling salesman problem," in Proceedings of the 2018 5th International Conference on Advanced Composite Materials and Manufacturing Engineering, Yunnan, China, June 2018.

[32] A. ElSaid, F. E. Jamiy, J. Higgins, B. Wild, and T. Desell, "Using ant colony optimization to optimize long short-term memory recurrent neural networks," in Proceedings of the Proceedings of the Genetic and Evolutionary Computation Conference, pp. 13-20, Kyoto, Japan, July2018.

[33] H. Cai, X. Lu, T. Du, Y. Wang, S. Xia, and D. Zhang, “A survey of artificial intelligence algorithm in power system Applications," in Proceedings of the 2019 IEEE 3rd International Electrical and Energy Conference (CIEEC), pp. 1902-1906, Beijing, China, September2019.

[34] X. Wang and K. Yang, "Economic load dispatch of renewable energy-based power systems with high penetration of largescale hydropower station based on multi-agent glowworm swarm optimization," Energy Strategy Reviews, vol. 26, Article ID 100425, 2019.

[35] N. Ben Guedria, "An accelerated differential evolution algorithm with new operators for multi-damage detection in plate-like structures," Applied Mathematical Modelling, vol. 80 , pp. 366-383, 2020.

[36] W. Deng, J. Xu, Y. Song, and H. Zhao, "Differential evolution algorithm with wavelet basis function and optimal mutation strategy for complex optimization problem," Applied Soft Computing, vol. 100, Article ID 106724, 2021.

[37] G. A. Vignaux and Z. Michalewicz, "A genetic algorithm for the linear transportation problem," IEEE transactions on systems, man, and cybernetics, vol. 21, no. 2, pp. 445-452, 1991.

[38] X. Li and S. Ma, "Multi-objective memetic search algorithm for multi-objective permutation flow shop scheduling problem," IEEE access, vol. 4, pp. 2154-2165, 2016.

[39] X. Li, X. Zhang, M. Yin, and J. Wang, "A genetic algorithm for the distributed assembly permutation flowshop scheduling problem," in Proceedings of the 2015 IEEE Congress on Evolutionary Computation (CEC), pp. 3096-3101, Sendai, Japan, May 2015.

[40] S. Roy and W. Crossley, "Hybrid multi-objective combinatorial optimization technique with improved compatibility between GA and gradient-based local search," in Proceedings of the 12th AIAA Aviation Technology, Integration, and Operations (ATIO) Conference and 14th AIAA/ISSMO Multidisciplinary Analysis and Optimization Conference, p. 5568, Indianapolis, IN, USA, September 2012.

[41] L. Zhou, R. Baldacci, D. Vigo, and X. Wang, "A multi-depot two-echelon vehicle routing problem with delivery options arising in the last mile distribution," European Journal of Operational Research, vol. 265, no. 2, pp. 765-778, 2018.

[42] R. W. Floyd, “Algorithm 97: shortest path," Communications of the ACM, vol. 5, no. 6, p. 345, 1962. 